\title{
Undifferentiated carcinoma of the gallbladder with endothelial differentiation: A case report and literature review
}

\author{
YOSHITAKA FURUYA ${ }^{1}$, KENZO HIROSHIMA ${ }^{2}$, TAKASHI WAKAHARA ${ }^{1}$, HARUTOSHI AKIMOTO ${ }^{1}$, \\ HIRONOBU YANAGIE ${ }^{3}$, KENICHI HARIGAYA ${ }^{4}$ and HIROSHI YASUHARA ${ }^{5}$ \\ ${ }^{1}$ Department of Surgery, Sodegaura Satsukidai Hospital, Chiba 299-0246; ${ }^{2}$ Department of Pathology,
} Tokyo Women's Medical University Yachiyo Medical Center, Chiba 276-8524; ${ }^{3}$ Department of Innovative Cancer Therapeutics, Alpha Particle and Immunotherapeutics, Meiji Pharmaceutical University, Tokyo 204-8588;

${ }^{4}$ Department of Pathology, Graduate School of Medicine, Chiba University, Chiba 260-8760;

${ }^{5}$ Surgical Center, University of Tokyo, Tokyo 113-8655, Japan

Received April 9, 2015; Accepted December 11, 2015

DOI: $10.3892 / \mathrm{mco} .2016 .1046$

\begin{abstract}
Undifferentiated carcinoma of the gallbladder is a rare cancer type with a poor prognosis. The present study described a case of undifferentiated gallbladder carcinoma of the spindle- and giant-cell type, according to the 2010 World Health Organization classification. Hematoxylin and eosin staining revealed that the tumor consisted of dense interlacing bundles of spindle-shaped cells. No evidence of cartilaginous, osseous or rhabdomyosarcomatous differentiation was observed. Immunohistochemical staining revealed that spindle- and polygonal-shaped cells of the undifferentiated carcinoma were positive for cytokeratin AE1/3, vimentin and vascular endothelial growth factor. Furthermore, numerous spindle-shaped cells were positive for cluster of differentiation (CD)34 and CD31, and certain spindle-shaped cells were positive for Factor VIII. These results suggested classification of the present case as 'undifferentiated gallbladder carcinoma with endothelial differentiation'.
\end{abstract}

\section{Introduction}

Undifferentiated carcinoma of the gallbladder predominantly comprising sarcomatous admixed with carcinomatous elements has been referred to as 'sarcomatoid carcinoma', 'so-called carcinosarcoma' and 'spindle-cell carcinoma', and is at times considered to be carcinosarcoma, while the terminology remains to be unified (1-9). Undifferentiated carcinoma of the gallbladder is now classified into four types,

Correspondence to: Dr Yoshitaka Furuya, Department of Surgery, Sodegaura Satsukidai Hospital, 5-21 Nagauraekimae, Sodegaura, Chiba 299-0246, Japan

E-mail: furuya@mail.satsuki-kai.or.jp

Key words: undifferentiated carcinoma, gallbladder, World Health Organization, endothelial differentiation, immunohistochemical staining according to the World Health Organization (WHO) classification (10), in addition to the diagnostic classification of carcinosarcoma. Similarly, the American Joint Committee on Cancer (AJCC) distinguishes between undifferentiated gallbladder carcinoma, sub-divided into i) the spindle- and giant-cell type and ii) the small-cell type, and carcinosarcoma (11). To further determine the characteristics of this rare carcinoma type, advanced immunostaining-based and gene analyses are required.

The present study reported on a case of undifferentiated gallbladder carcinoma of the spindle- and giant-cell type with endothelial differentiation and performed a review of the literature.

\section{Case report}

A female patient (age, 61 years) was admitted to Sodegaura Satsukidai Hospital (Sodegaura,Japan) with the chief complaint of right hypochondralgia with Murphy's sign. The patient had diabetes mellitus. Laboratory findings revealed mild inflammation and hyperglycemia; the white blood cell count was $10,600 / \mathrm{mcl}$ (normal range, 4,000-9,000 mcl), C-reactive protein levels were $3.41 \mathrm{mg} / \mathrm{dl}$ (normal range, $<0.5 \mathrm{mg} / \mathrm{dl}$ ) and fasting blood glucose levels were $210 \mathrm{mg} / \mathrm{dl}$ (normal range, $70-110 \mathrm{mg} / \mathrm{dl}$ ). Examination for tumor markers revealed that carcinoembryonic antigen and carbohydrate antigen 19-9 were within normal limits. Abdominal computed tomography (CT) revealed acute cholecystitis with a thickened, edematous wall of the gallbladder (Fig. 1), a single stone with a diameter of $20 \mathrm{~mm}$ in the neck of the gallbladder and no demonstrable lymph nodes. Ultrasonography (US) revealed identical results to $\mathrm{CT}$, including debris in the gallbladder and a thickened gallbladder wall. Drip infusion cholangiography CT demonstrated that the cystic duct was occluded despite improvement of the edematous gallbladder wall after conservative treatment with antibiotics for 2 weeks at the Department of Internal Medicine of Sodegaura Satsukidai Hospital (Sodegaura, Japan). One month after leaving our hospital, laparoscopic cholecystectomy was performed, and a diagnosis of chronic cholecystitis with a stone was made. 


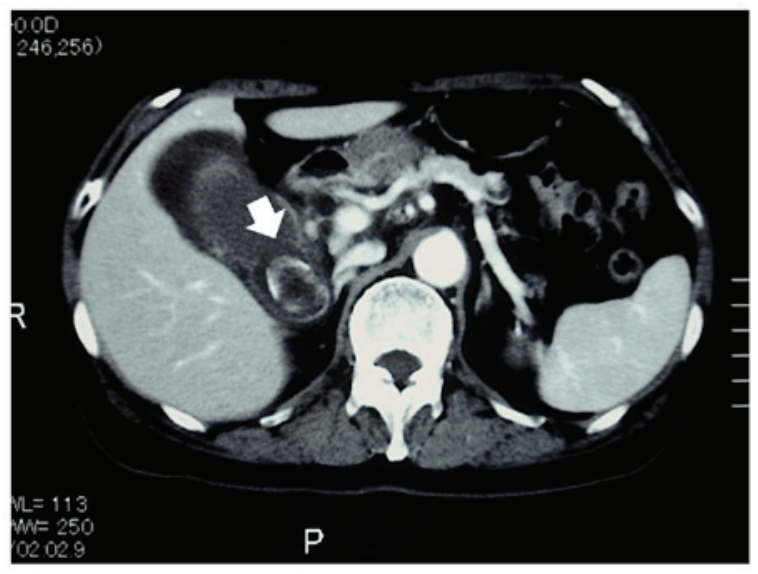

Figure 1. Computed tomography demonstrated that the wall of the gallbladder with a single stone (white arrow) at the neck was edematous.

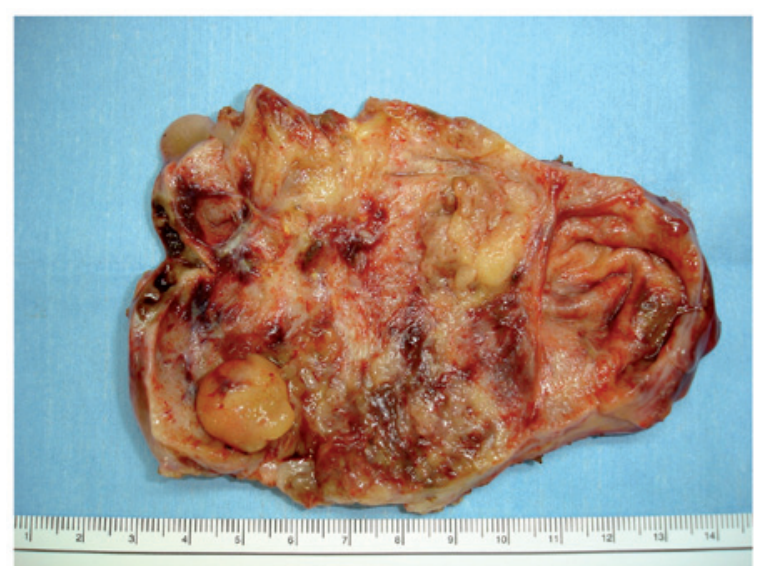

Figure 2. The mucosa of the resected gallbladder was atrophic with two slight elevations in the body and fundus, and a smooth mass in the fundus.

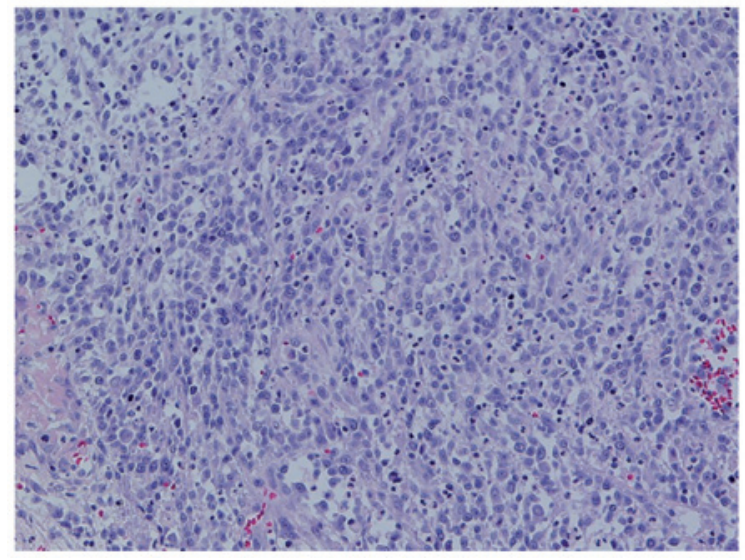

Figure 3. Hematoxylin and eosin-stained tissue section showing spindle- and polygonal-shaped cells.

The resected gallbladder was $11 \times 7 \mathrm{~cm}$ in length, and its whitish-yellow mucosa was atrophic with two slight elevations measuring $2.0 \times 1.5$ and $1.5 \times 1.5 \mathrm{~cm}$ in the body and fundus, respectively, as well as a smooth mass measuring $1.5 \times 1.5 \mathrm{~cm}$ in the fundus (Fig. 2). Histological examination revealed undifferentiated carcinoma with spindle- and polygonal-shaped

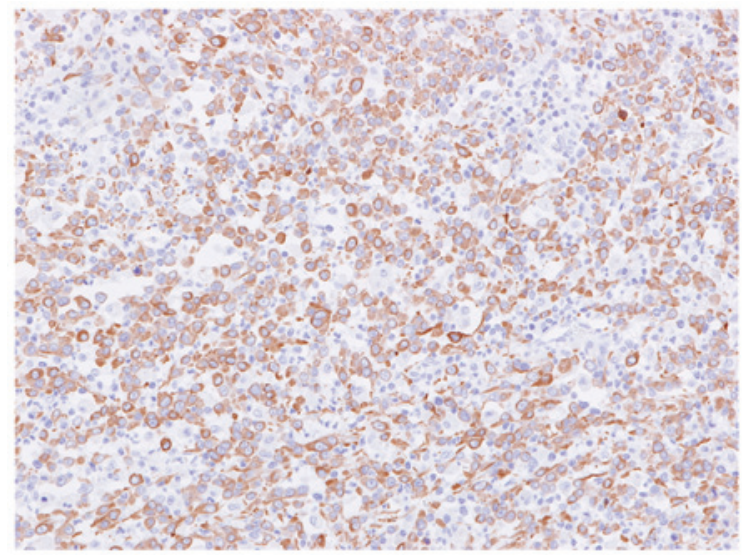

Figure 4. Immunohistochemical staining showing positivity of the spindle-shaped cells for cytokeratin AE1/3.

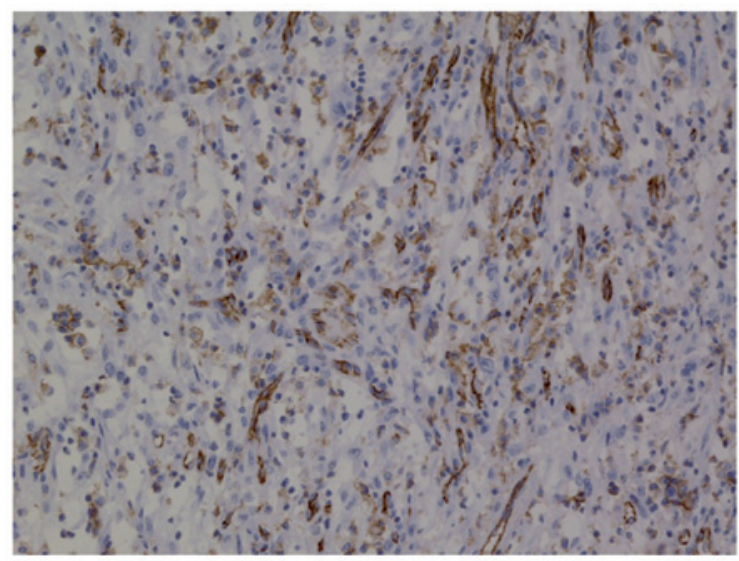

Figure 5. Immunohistochemical staining showing positivity of the spindle-shaped cells for CD31.

cells (Fig. 3). No evidence of cartilaginous, osseous or rhabdomyosarcomatous differentiation was found. The tumor cells were spread throughout approximately two-thirds of the gallbladder with invasion of perimuscular connective tissue; however, no cancer was observed in the neck of the gallbladder, the liver or sentinel lymph nodes. The pathological stage was T2 N0 M0, stage II according to the Tumor-Nodes-Metastasis classification. Immunohistochemical staining revealed that spindle- and polygonal-shaped cells were positive for cytokeratin (CK) AE1/3 (Fig. 4), vimentin and vascular endothelial growth factor (VEGF) (data not shown). Furthermore, numerous spindle-shaped cells were positive for CD31 (Fig. 5) and CD34, and certain spindle-shaped cells were positive for Factor VIII (data not shown).

The post-operative course was uneventful. However, at two months following surgery, CT demonstrated liver metastasis. The patient rejected hepatectomy, but consented to chemotherapy. After the first administration of gemcitabine and cis-diamminedichloro-platinum (CDDP), the liver tumors had responded well and the tumor size was considerably reduced; the maximum tumor size $(5 \mathrm{~cm}$ diameter was measured by $\mathrm{CT}$ ) in the liver decreased by $50 \%$. After two cycles, the regimen was discontinued due to the appearance of Grade 2 or 3 side effects (vomiting, bone marrow suppression and renal 
Table I. Characteristics of undifferentiated carcinoma and carcinosarcoma.

A, Undifferentiated carcinoma

\begin{tabular}{|c|c|c|c|c|c|c|c|}
\hline Author, year & $\begin{array}{c}\text { No. of } \\
\text { cases }\end{array}$ & $\begin{array}{c}\text { Mean } \\
\text { age, years }\end{array}$ & $\begin{array}{c}\text { Female-to-male } \\
\text { ratio }\end{array}$ & $\begin{array}{l}\text { Median tumor } \\
\text { size, cm (mean) }\end{array}$ & $\begin{array}{l}\text { Median survival, } \\
\text { months (mean) }\end{array}$ & $\begin{array}{c}1 \text {-year } \\
\text { survival rate }(\%)\end{array}$ & Refs. \\
\hline Guo et al, 1988 & 21 & 66.3 & 2.50 & ND & $3.0(10.0)$ & 18.2 & (2) \\
\hline Nishihara et al, 1993 & 11 & 66.5 & 2.67 & $5.8(6.7)$ & $3.0(8.1)$ & 18.2 & (3) \\
\hline Akatsu et al, 2005 & 18 & 67.5 & 2.60 & $5.0(6.1)$ & $3.0(6.9)$ & 12.5 & (4) \\
\hline Mizusaki et al, 2007 & 18 & 65.7 & 1.57 & $7.0(7.2)$ & $7.0(11.1)$ & 38.5 & $(5)$ \\
\hline Hu et al, 2010 & 10 & 67.0 & 4.00 & $5.2(\mathrm{ND})$ & 9.0 (ND) & ND & (6) \\
\hline Park et al, 2014 & 8 & 57.2 & 7.00 & $5.0(5.8)$ & $7.3(18.0)$ & 37.5 & (7) \\
\hline
\end{tabular}

B, Carcinosarcoma

\begin{tabular}{|c|c|c|c|c|c|c|c|}
\hline Author, year & $\begin{array}{l}\text { No. of } \\
\text { cases }\end{array}$ & $\begin{array}{c}\text { Mean } \\
\text { age, years }\end{array}$ & $\begin{array}{l}\text { Female-to-male } \\
\text { ratio }\end{array}$ & $\begin{array}{c}\text { Median tumor } \\
\text { size, } \mathrm{cm} \text { (mean) }\end{array}$ & $\begin{array}{c}\text { Median survival, } \\
\text { months (mean) }\end{array}$ & $\begin{array}{c}1 \text {-year } \\
\text { survival rate }(\%)\end{array}$ & Refs. \\
\hline Okabayashi et al, 2010 & 28 & 67.4 & 2.62 & $8.5(8.6)$ & $5.5(10.8)$ & 33.3 & $(13)$ \\
\hline Gao et al, 2015 & 21 & 69.0 & 1.63 & $6.5(7.0)$ & $7.0(13.7)$ & 50.0 & (14) \\
\hline
\end{tabular}

ND, not described.

disfunction), and tegafur, gimeracil and oteracil potassium (S-1) were administered. The patient succumbed to multiple liver metastases and peritoneal dissemination at $~ 5$ months following surgery.

\section{Discussion}

In 2000, a new WHO classification of undifferentiated carcinoma was published (12), according to which undifferentiated carcinoma of the gallbladder are classified into the following four types: i) Undifferentiated carcinoma, spindle-and giant-cell type; ii) undifferentiated carcinoma with osteoclast-like giant cells; iii) undifferentiated carcinoma, small-cell type; and iv) undifferentiated carcinoma, nodular or lobular type. In the new 4th edition of the WHO classification of undifferentiated gallbladder carcinoma from 2010 (10), the pathological description is more concise compared with that in the classification from 2000 (12). Even after the the 2000 version of WHO classification was published, the terms 'sarcomatoid carcinoma', 'so-called carcinosarcoma' and 'spindle-cell carcinoma' have been used in the English literature for the same diagnosis of undifferentiated carcinoma of the gallbladder. However, the use of the pathological diagnostic name 'undifferentiated carcinoma' has gradually increased, while the use of the other names has decreased, but still occurs. The various above-mentioned diagnostic names must be unified under the name 'undifferentiated carcinoma' immediately, so that the characteristics, prognosis and novel treatments of this rare tumor type can be clarified by meta-analysis. The present case was properly classified as 'undifferentiated carcinoma, spindle- and giant-cell type' according to the WHO classification. To the best of our knowledge, the present study provided the first case report of 'undifferentiated carcinoma with endothelial differentiation' diagnosed using sub-type analysis. Notably, the final diagnosis was made not only based on morphological findings, but also using immunohistochemical staining.

Although the WHO and AJCC differentiate between undifferentiated carcinoma and carcinosarcoma, certain pathologists classify them into the same group. The prognosis for undifferentiated carcinoma as well as carcinosarcoma of the gallbladder is poor. The present study performed an analysis of previous studies containing statistically significant, reliable data, while excluding those containing combined data for undifferentiated carcinoma and carcinosarcoma. The following groups were analyzed in order to clarify their clinical characteristics and differences: A) The undifferentiated carcinoma (2-5,7) and sarcomatoid carcinoma (6) group, and B) the carcinosarcoma group $(13,14)$. The data from each article were re-evaluated and re-calculated as required. The results of the analysis, which are shown in Table I, showed that the patients' mean age was 66.6 years and that a high percentage of affected patients were female (female-to-male ratio, 1.57-7.00). Of note, in group $\mathrm{A}$, the prognostic data in more recent studies (5-7) tended to be improved compared with those in earlier studies (2-4). Among the more recent studies, no significant difference between the prognostic data in groups A $(5-7)$ and B $(13,14)$ was present; however, the tumor size in group B was slightly larger compared with that in group A. The implementation of diagnostic methods, including CT, US and magnetic resonance imaging to detect small-sized tumors, the development of extended radical surgery may have accounted for the abovementioned findings. The differences in the malignant potential between groups A and B may be 
based on the fact that the cells have different origins: True carcinosarcoma is derived from totipotent stem cells, which separately differentiate into epithelial and sarcomatous cells, while undifferentiated carcinoma is a morphological variant of carcinoma, which is transformed to exhibit sarcomatous features (4). The prognosis of patients with undifferentiated carcinoma of the gallbladder may be identical or slightly worse compared with that of patients with carcinosarcoma; however, this requires further assessment by future meta-analyses of data from patients worldwide.

Certain studies have pointed out the difficulty of treating undifferentiated carcinoma of the gallbladder because of the large tumor size, liver and lymph node metastasis, and peritoneal dissemination $(1,15,16)$, even if it is detected without patient's symptom. Although surgical resection is the predominant treatment, a study by Doval et al (17) reported the use of palliative chemotherapy in a case of sarcomatoid carcinoma; however, chemotherapy and radiotherapy were generally shown not to be beneficial by numerous other studies $(5,9,13,16,18-21)$. In the present case, the secondary liver tumors responded well to adjuvant gemcitabine and CDDP, and the tumor size decreased considerably. The regimen was discontinued due to the appearance of side effects, and tegafur, gimeracil and oteracil potassium (S-1) were administered. Owing to the rapid growth of the patient's tumor, she succumbed to it $\sim 5$ months following surgery. VEGF inhibitors, which are not approved for patients with undifferentiated gallbladder carcinoma by the National Health Insurance Program of Japan, may have improved the prognosis of the present case, as the tumor showed endothelial differentiation and VEGF-positive staining. It is expected that the prognosis of undifferentiated gallbladder carcinoma will be improved in the future by using gene analysis and gene therapy.

In conclusion, the present study reported on a case histopathologically identified as undifferentiated carcinoma of the gallbladder. However, immunohistochemical staining revealed characteristics that differed from those of other studies. The present case was diagnosed as 'undifferentiated carcinoma with endothelial differentiation' due to its immunohistochemical features.

\section{References}

1. Kubota K, Kakuta Y, Kawamura S, Abe Y, Inamori M, Kawamura H, Kirikoshi H, Kobayashi N, Saito S and Nakajima A: Undifferentiated spindle-cell carcinoma of the gallbladder: An immunohistochemical study. J Hepatobiliary Pancreat Surg 13: 468-471, 2006

2. Guo KJ, Yamaguchi K and Enjoji M: Undifferentiated carcinoma of the gallbladder. A clinicopathologic, histochemical, and immunohistochemical study of 21 patients with a poor prognosis. Cancer 61: 1872-1879, 1988.

3. Nishihara K and Tsuneyoshi M: Undifferentiated spindle cell carcinoma of the gallbladder: A clinicopathologic, immunohistochemical and flow cytometric study of 11 cases. Hum Pathol 24 $1298-1305,1993$.
4. Akatsu T, Ueda M, Shimazu M, Wakabayashi G, Aiura K, Tanabe M, Kawachi S, Kameyama K and Kitajima M: Primary undifferentiated spindle-cell carcinoma of the gallbladder presenting as a liver tumor. J Gastroenterol 40: 993-998, 2005.

5. Mizusaki K, Saito E and Kobayashi H: A case of undifferentiated carcinoma of the gallbladder with rapidly progress after operation. J Jpn Biliary Assoc 21: 567-573, 2007 (Japanese).

6. Hu ZH, Li ZW, Shen L, Zhang M and Zheng SS: Surgical therapy and prognosis of sarcomatoid carcinoma of the gallbladder. Hepatobiliary Pancreat Dis Int 9: 175-179, 2010.

7. Park HJ, Jang KT, Choi DW, Heo JS and Choi SH: Clinicopathologic analysis of undifferentiated carcinoma of the gallbladder. J Hepatobiliary Pancreat Sci 21: 58-63, 2014.

8. Zhang L, Chen Z, Fukuma M, Lee LY and Wu M: Prognostic significance of race and tumor size in carcinosarcoma of gallbladder: A meta-analysis of 68 cases. Int Clin Exp Pathol 1: 75-83, 2008.

9. Hotta T, Tanimura H, Yokoyama S, Ura K and Yamaue H: So-called carcinosarcoma of the gallbladder; spindle cell carcinoma of the gallbladder: Report of a case. Surg Today 32: 462-467, 2002

10. Albores-Saavedra J, Adsay NV, Crawford JM, Klimstra DS, Kloppel G, Sripa B, Tsui WMS and Paradis V: Carcinoma of the gallbladder and extrahepatic bile ducts. In: WHO Classification of Tumors of the Digestive System 4th ed. Bosman FT, Carneiro F, Hruban RH, Theise ND (eds.) IARC Press: Lyon, pp266-pp273, 2010.

11. Edge SB and Compton CC: The american joint committee on cancer: The 7th edition of the AJCC cancer staging manual and the future of TNM. Ann Surg Oncol 17: 1471-1474, 2010.

12. Albores-Saavedra J, Scoazec JC, Wittekind C, Sripa B, Menck HR, Soehendra N and Sriram PVJ: Carcinoma of the gallbladder and extrahepatic bile ducts. In: World Health Organization Classification of Tumours. Pathology and Genetics of Tumours of the Digestive System. IARC Press, Lyon, pp206-pp214, 2000.

13. Okabayashi T, Sun ZL, Montgomey RA and Hanazaki K: Surgical outcome of carcinosarcoma of the gall bladder: A review. World J Gastroenterol 15: 4877-4882, 2009.

14. Gao S, Huang L, Dai S, Chen D, Dai R and Shan Y: Carcinosarcoma of the gallbladder: A case report and review of the literature. Int $\mathrm{J}$ Clin Exp Pathol 8: 7464-7469, 2015.

15. Badmos KB, Salah Seada L, Fahad Al Rashid F and Oreiby HA: Undifferentiated spindle-cell carcinoma of the gallbladder: A report of a case, an immunohistochemistry profile, and a review of the literature. Case Rep Pathol 2013: 267194, 2013.

16. Nagata J, Kijima H, Watanabe $\mathrm{N}$ and Mine T: Undifferentiated carcinoma of the gallbladder. Nihon Rinsho 3: (Suppl 73): S769-S773, 2015 (In Japanese).

17. Doval DC, Azam S, Mehta A, Pruthi A, Batra U, Choudhury KD and Kumar K: A report of sarcomatoid carcinoma of the gallbladder treated with palliative deocetaxel and gemcitabine chemotherapy. J Gastrointest Cancer 45: 270-274, 2014.

18. Ajiki T, Nakamura T, Fujino Y, Suzuki Y, Takeyama Y, Ku Y, Kuroda Y and Ohbayashi C: Carcinosarcoma of the gallbladder with chondroid differentiation. J Gastroenterol 37: 966-971, 2002.

19. Kataria K, Yadav R and Seenu V: Sarcomatoid carcinoma of the gall bladder. J Surg Case Rep 2012: 5, 2012.

20. Huguet KL, Hughes CB and Hewitt WR: Gallbladder carcinocsarcoma: A case report and literature review. J Gastrointest Surg 9: 818-821, 2005.

21. Liu KH, Yeh TS, Hwang TL, Jan YY and Chen MF: Surgical management of gallbladder sarcomatoid carcinoma. World J Gastroenterol 15: 1876-1879, 2009. 